\title{
Xeroderma pigmentosa with ocular association: Case report
}

\author{
Achyut N. Pandey ${ }^{1^{*}}$, Krishna Kuldeep ${ }^{1}$, Ameeta Koul ${ }^{1}$, Manoj Tyagi ${ }^{1}$, Parul Singh ${ }^{1}$, \\ Parmeshwari Das Sharma ${ }^{1}$, Deepak Dimri ${ }^{2}$ \\ ${ }^{1}$ Department of Ophthalmology, VCSG Government Medical College and Research Institute, Srinagar Garhwal, India; \\ *Corresponding Author: achyutpandey@gmail.com \\ ${ }^{2}$ Department of Dermatology, VCSG Government Medical College and Research Institute, Srinagar Garhwal, India
}

Received 13 September 2013; revised 10 October 2013; accepted 30 October 2013

Copyright (C) 2013 Achyut N. Pandey et al. This is an open access article distributed under the Creative Commons Attribution License, which permits unrestricted use, distribution, and reproduction in any medium, provided the original work is properly cited.

\begin{abstract}
Xeroderma pigmentosum is a rare, autosomal recessive disease caused by a defect in DNA repair. Patients with xeroderma pigmentosum often have cutaneous and ocular sun sensitivity, freckle-like skin pigmentation, multiple skin and eye cancers, and, in some patients, progressive neurodegeneration. Xeroderma pigmentosum predominantly affects the ultraviolet (UV) exposed ocular surface, resulting in eyelid atrophy and cancers, corneal dryness, exposure keratopathy, and conjunctival tumors. General features included parental consanguinity (40\%), familiarity $(60 \%)$, onset of symptoms in the first 2 years (50\%), malignant skin neoplasms (60\%), and carcinoma of the tongue (20\%). Among the ocular features, $50 \%$ of patients presented with photophobia. Lid freckles or atrophic skin lesions were seen in all patients. Lower lid tumours were seen in $30 \%$, chronic conjunctival congestion in $40 \%$, corneal opacification in $40 \%$, squamous cell carcinoma of limbus in $20 \%$, bi-

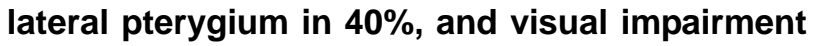
in $50 \%$. We report the clinical history and ocular pathology of a boy who is having xeroderma pigmentosum with ocular manifestations. The ophthalmic manifestations of xeroderma pigmentosum are discussed and reviewed with respect to this report and other cases in the literature. These cases illustrate the role of DNA repair in protection of the eyes from UV damage and neuron degeneration of the retina.
\end{abstract}

Keywords: Ciliary Body Hamartoma; Ocular Pathology; Optic Atrophy; Xeroderma Pigmentosum; Pigmentary Retinal Degeneration

\section{INTRODUCTION}

Xeroderma pigmentosum (XP), first described by Hebra and Kaposi in 1874, presents in early childhood with photophobia, photosensitivity, cutaneous pigmentary changes, and a predisposition for malignancy in sunexposed mucocutaneous areas and ocular structures [1]. XP patients have a defect in DNA repair related to the nucleotide excision repair pathway [2] or a bypass polymerase pathway [3]. Mutations in XPA or XPC are present in approximately $50 \%$ of patients [4]. The disease is extremely rare in North America and Europe (frequency $1 / 1,000,000)$ [5], but is more common in areas of the world with increased consanguinity, including Japan (frequency 1/22,000) [6], the Middle East, North Africa, and India [5].

XP often presents with cutaneous manifestations within the first two years of life [7]. Patients are predisposed to malignant skin neoplasms in the face, neck and upper trunk, the tip of the tongue, and the anterior eye surfaces. Ocular disease is evident in at least $40 \%$ of XP patients and often causes visual impairment. Clinically apparent ocular disease includes eyelid atrophy and tumors, corneal sicca and opacification, exposure keratitis, pterygium, and chronic conjunctival injection. Here, we report the clinical features of a boy in which we found classic findings of this disease and ocular manifestations.

\section{CASE}

\section{Case 1}

A 6-year-old boy comes to the OPD with c/o skin lesions all around the body since birth. No h/o treatment before. No h/o itching, drug use, injury. No other sibling having the same problem. No parental consanguity. No similar illness in the family. Birth history normal, normal 
uneventful vaginal delivery. Normal growth. The chief complaints were photophobia and defective vision.

On examination-presence of blisters all over face, trunk, abdomen and legs (Figures 1 and 2). The lesions are excoriating. The lesions are dry, nontender, raised and red to pink in colour. On eye examination- both eyes having projection of rays present and perception of light inaccurate. The skin of the lid is excoriated. Presence of growth in both the lids is suggesting of lid malignancy. Conjunctiva is condested with both limbal and bulbar conjunctival growth suggesting of basal cell carcinoma. Cornea is totally opaque with vascularisation (Figures 3 and 4). Other details could not be made out. Neurological examination is within normal limit. All other investigations include hemogram, lipid profile. Liver and renal function tests, ultrasound abdomen were found to be normal. Patient is advised for phototherapy with radiation and enucleation/exanteration for ocular lesions. Prognosis explained to parents.

Skin biopsy has been done with diagnosis of xeroderma pigmentosa.

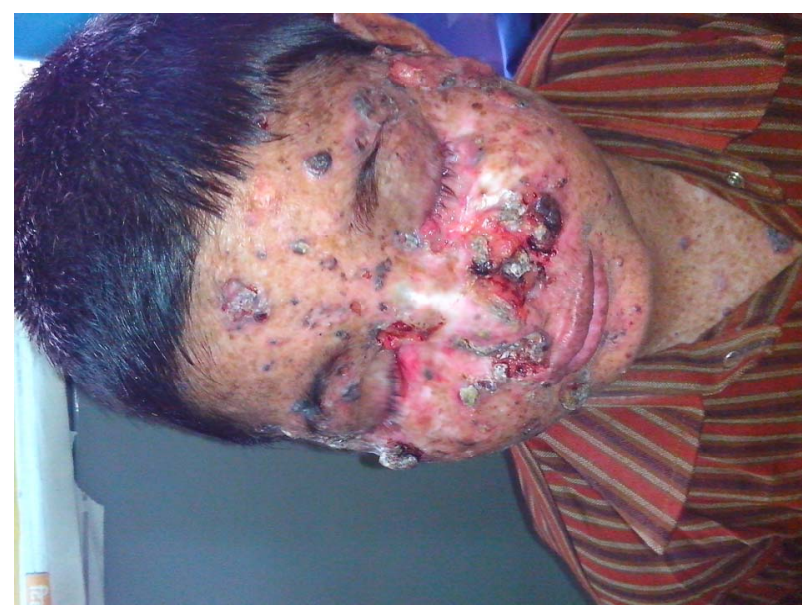

Figure 1. Face showing blisters.

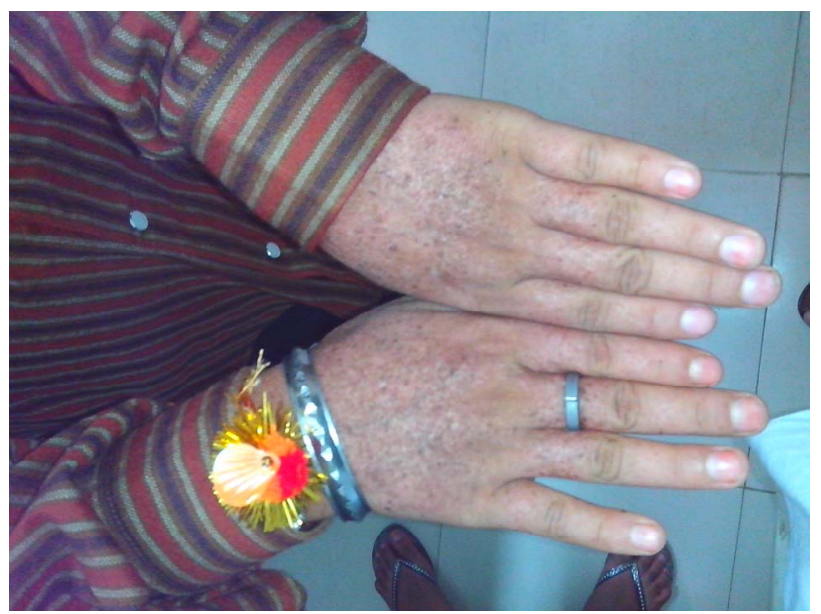

Figure 2. Hand showing XP lesions.

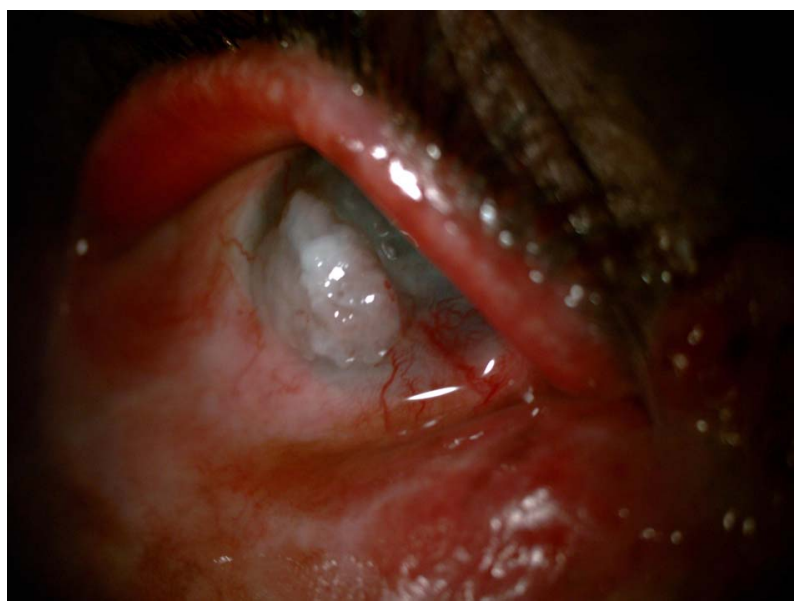

Figure 3. Right eye.

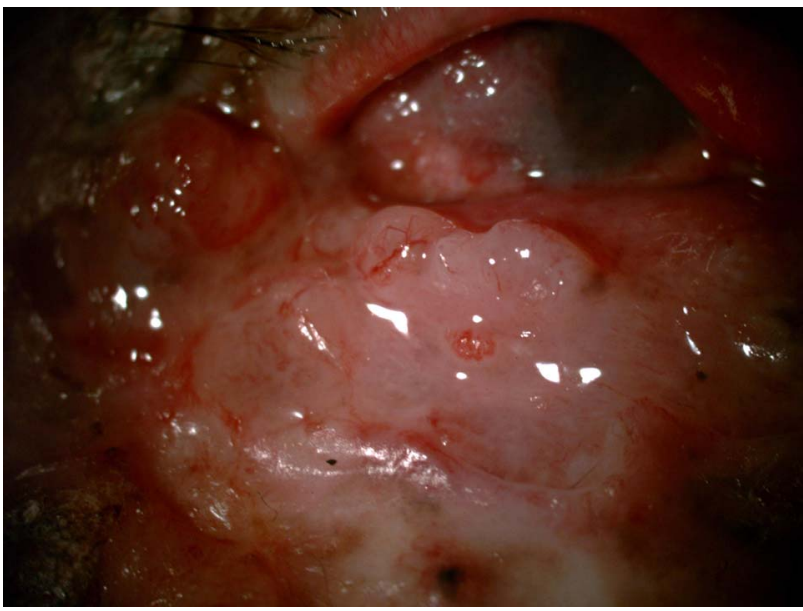

Figure 4. Left eye.

\section{LITERATURE REVIEW AND DISCUSSION}

\subsection{Systemic Features and Genetics of XP}

$\mathrm{XP}$ is an autosomal recessive disease of defective DNA repair that affects males and females equally and is frequently symptomatic in childhood [2]. Defects in nucleotide excision repair can lead to three diseases: XP, Cockayne syndrome, and trichothiodystrophy. XP and Cockayne syndrome both present with photosensitivity and progressive neurological degeneration [7]. XP has a greatly increased risk of sun-induced cancers, and Cockayne patients have normal cancer risk. Retinitis pigmentosa retinopathy is well recognized in Cockayne syndrome, while retinal abnormalities are not common in XP patients [8]. Cockayne syndrome patients may have poor vision with pupillary unresponsiveness, hypermetropia, nystagmus, hypoplastic irides, cataract, vitreous floaters, optic atrophy, and global progressive pigmentary retinal degeneration [9]. While Cockayne syndrome also presents with photosensitivity and neurologic 
dysfunction, patients tend to have a "bird-like" face, microcephaly, premature aging, dwarfism, cachexia, sunken eyes, and usually die before age 30 [10]. Though the genetic defects are closely related, these diseases have different systemic and ocular manifestations [9].

Genetic defects in XP are heterogeneous, resulting from defects in 8 different genes (complementation groups) [11]. Defects in nucleotide excision repair lead to premature sunlight-induced damage including hyperpigmentation, hypopigmentation, lentigos, telangectasias, actinic keratoses, and atrophy. Cutaneous symptoms usually present before 2 years of age, and the median age of first skin neoplasm is under 10 years.

Progressive neurologic symptoms are present in about $25 \%$ of affected patients [3]. Neurologic abnormalities include cognitive impairment, acquired microcephaly, abnormal motor activity, areflexia, sensorineural hearing loss, and abnormal speech. Studies suggest that neuronal degeneration in XP is a primary process, possibly caused by the inability to repair DNA that has been damaged by oxidative damage from endogenous metabolites [12].

The majority of neoplasms in patients with XP occur in areas that are exposed to UV-radiation, including skin, anterior surfaces of the eye, and tip of the tongue [13]. There is an increased frequency of central nervous system tumors. Internal neoplasms may be related to environmental carcinogen exposure that causes DNA damage, which, like UV-damage, is poorly repaired in XP patients. Overall, XP patients have a $70 \%$ probability of survival to 40 years of age.

\subsection{Clinical Ocular Manifestations of XP}

Ocular disease is evident in at least $40 \%$ of XP patients, and blepharospasm and photophobia are common symptoms. Eyelid skin changes reflect local skin changes, including usually erythema, pigmentation, atrophy, and malignant change [14]. Telangectasias, loss of lashes, and chronic blepharitis are also seen [14]. Atrophic scarred skin may cause ectropion of the lower eyelid and symblepharon [6]. Lower lid loss may result in exposure keratitis, edema, and even corneal ulceration and perforation [15]. Corneal opacification, neovascularization, pterygia, and band keratopathy are common, and bandshaped nodular dystrophy and squamous cell carcinomas have also been reported. Conjunctival involvement usually includes conjunctivitis, pinguecula, symblepharon, melanosis, and tumors developing from the interpalpebral zone of the limbus [14]. Limbal tumors, especially pterygia, are common, and squamous cell carcinomas, malignant melanomas and limbal stem cell deficiency have been reported. The iris can be affected by iritis, stromal atrophy, pigment abnormalities, and, rarely, melanoma [16]. Orbital tumors include basal cell carcinomas, squamous cell carcinomas, and melanomas. As the posterior segment is protected from UV damage by the cornea and lens, fundus abnormalities are not common; however, choroidal melanoma rarely develops [17]. Unlike Cockayne syndrome, which is clinically associated with pigmentary retinal degeneration including retinitis pigmentosa, retinal abnormalities have not previously been reported in XP patients.

Clinical management of XP includes avoidance of sunlight, minimizing UV and cigarette smoke exposure, early excision of skin lesions, and genetic counseling [3]. Oral 13-cis retinoic acid has been shown to reduce the incidence of new cancers in XP patients [18]. Ophthalmic management includes UV-absorbing sunglasses with side shields, artificial tears, intermittent topical steroids, surveillance for ocular neoplasms, and management of complications. Eyelid and conjunctival cancers are the most commonly reported. Current management of eyelid tumors is complete resection using Mohs' micrographic surgery, with or without reconstruction, or other tissue sparing techniques [19]. Malignant conjunctival tumors that can be excised should be removed and treated with adjuvant cryotherapy/irradiation/topical chemotherapy [20]. Some malignant limbal tumors can be removed by iridocyclectomy, while others may require enucleation [21]. Corneal tumors have been managed with keratoplasty and topical chemotherapy. Iris tumors may be managed with local excision, plaque radiotherapy, or enucleation [22]. Choroidal melanomas are commonly managed with plaque radiotherapy, but this has not been specifically studied in XP patients [23]. If a tumor involves the orbit, imaging is required, and surgical excision with adjunctive radiation can be therapeutic [24]. Despite their extreme sensitivity to UV light, XP patients can be treated with standard doses of radiation for treatment of neoplasms [24]. Large or invasive ocular or orbital tumors may require enucleation and/or orbital exenteration.

\section{CONCLUSION}

Patients with XP often exhibit ocular changes. Beside the light-dependent degenerative and inflammatory manifestations of the lids, the conjunctiva and the cornea patients with XP also develop malignancies early in life. The majority of patients suffer from dry eye symptoms. XP behaved aggressively in both malignancy profile and visual outcome. Various types of malignant ocular-cutaneous tumours relating to sunlight developed in xeroderma pigmentosum patients. These disorders are more prevalent in severe and moderate forms of xeroderma pigmentosum. Lesions occur almost exclusively in the eyelids, conjunctiva, limbus and/or cornea. The rapid regression of these tumours, particularly in the cornea and limbus, may cause blindness, emphasising the importance of early management and regular monitoring 
of patients in order to allow early diagnosis of this condition, thereby ensuring the least mutilant treatment possible.

\section{ACKNOWLEDGEMENTS}

We acknowledge our patient and his family for their contributions to our research. The author is thankful to Mr. Divyam Pandey and Anil Semwal for help in finalising this report.

\section{REFERENCES}

[1] Hebra, F. and Kaposi, M. (1874) On diseases of the skin including exanthemata. New Sydenham Society, 61, 252258.

[2] Cleaver, J.E. (1968) Defective repair replication of DNA in xeroderma pigmentosum. Nature, 218, 652-656. http://dx.doi.org/10.1038/218652a0

[3] Kraemer, K.H. (2008) In: Pagon, R.A., Bird, T.C., Dolan, C.R. and Stephens, K., Eds., Xeroderma Pigmentosum, University of Washington, Seattle.

[4] Kleijer, W.J., Laugel, V. and Berneburg, M., et al. (2008) Incidence of DNA repair deficiency disorders in western Europe: Xeroderma pigmentosum, Cockayne syndrome and trichothiodystrophy. DNA Repair (Amst), 7, 744-750. http://dx.doi.org/10.1016/j.dnarep.2008.01.014

[5] Hirai, Y., Kodama, Y., Moriwaki, S., et al. (2006) Heterozygous individuals bearing a founder mutation in the XPA DNA repair gene comprise nearly $1 \%$ of the Japanese population. Mutation Research, 601, 171-178. http://dx.doi.org/10.1016/j.mrfmmm.2006.06.010

[6] Reese, A.B. and Wilber, I.E. (1943) The eye manifestations of xeroderma pigmentosum. American Journal of Ophthalmology, 26, 901-911.

[7] O’Malley, P.F. and Allen, R.A. (1967) Peripheral cystoid degeneration of the retina. Incidence and distribution in 1000 autopsy eyes. Archives of Ophthalmology, 77, 769776. http://dx.doi.org/10.1001/archopht.1967.0098002077101 $\underline{0}$

[8] Pearce, W.G. (1972) Ocular and genetic features of Cockayne's syndrome. Canadian Journal of Ophthalmology, 7, 435-444.

[9] Dollfus, H., Porto, F., Caussade, P., et al. (2003) Ocular manifestations in the inherited DNA repair disorders. Survey of Ophthalmology, 48, 107-122. http://dx.doi.org/10.1016/S0039-6257(02)00400-9

[10] Brumback, R.A., Yoder, F.W., Andrews, A.D., et al. (1978) Normal pressure hydrocephalus. Recognition and relationship to neurological abnormalities in Cockayne's syndrome. Archives of Neurology, 35, 337-345. http://dx.doi.org/10.1001/archneur.1978.00500300011002

[11] Broughton, B.C., Cordonnier, A., Kleijer, W.J., et al. (2002) Molecular analysis of mutations in DNA polymerase ETA in xeroderma pigmentosum-variant patients. Proceedings of the National Academy of Sciences of the United States of America, 99, 815-820.

\section{http://dx.doi.org/10.1073/pnas.022473899}

[12] Robbins, J.H., Kraemer, K.H., Merchant, S.N. and Brumback, R.A. (2002) Adult-onset xeroderma pigmentosum neurological disease-Observations in an autopsy case. Clinical Neuropathology, 21, 18-23.

[13] Chidzonga, M.M., Mahomva, L., Makunike-Mutasa, R. and Masanganise, R. (2009) Xeroderma pigmentosum: A retrospective case series in Zimbabwe. Journal of Oral and Maxillofacial Surgery, 67, 22-31. http://dx.doi.org/10.1016/j.joms.2007.09.026

[14] El Hefnawi, H., Rasheed, A. and Xeroderma, P. (1966) A report of further six cases. The Journal of the Egyptian Medical Association, 49, 419-434.

[15] Blanksma, L.J., Donders, P.C. and van Voorst, V.P.C. (1986) Xeroderma pigmentosum and keratoconus. Documenta Ophthalmologica, 64, 97-103. http://dx.doi.org/10.1007/BF00166690

[16] Johnson, M.W., Skuta, G.L., Kincaid, M.C., et al. (1989) Malignant melanoma of the iris in xeroderma pigmentosum. Archives of Ophthalmology, 107, 402-407. http://dx.doi.org/10.1001/archopht.1989.0107001041203 $\underline{6}$

[17] Kitagawa, K.O.T. and Inoue, M. (1981) Choroidal malignant melanoma occurring in a patient with xeroderma pigmentosum. Folia Ophthalmol Jpn, 32, 657-663.

[18] Kraemer, K.H., DiGiovanna, J.J., Moshell, A.N., et al. (1988) Prevention of skin cancer in xeroderma pigmentosum with the use of oral isotretinoin. The New England Journal of Medicine, 318, 1633-1637. http://dx.doi.org/10.1056/NEJM198806233182501

[19] Cook, Jr., B.E., and Bartley, G.B. (2001) Treatment options and future prospects for the management of eyelid malignancies: An evidence-based update. Ophthalmology, 108, 2088-2098. http://dx.doi.org/10.1016/S0161-6420(01)00796-5

[20] Kearsley, J.H., Fitchew, R.S. and Taylor, R.G. (1988) Adjunctive radiotherapy with strontium-90 in the treatment of conjunctival squamous cell carcinoma. International Journal of Radiation Oncology, Biology, Physics, 14, 435-443. http://dx.doi.org/10.1016/0360-3016(88)90257-X

[21] Shields, C.L. and Shields, J.A. (2004) Tumors of the conjunctiva and cornea. Survey of Ophthalmology, 49, 3-24. http://dx.doi.org/10.1016/j.survophthal.2003.10.008

[22] Shields J. (2008) Melanocytic tumors of the iris stroma: Intraocular tumors: Atlas and textbook. 2nd Edition, Chapter 2, Lippincott Williams \& Wilkins, Philadelphia, 22.

[23] Limawararut, V., Leibovitch, I., Sullivan, T. and Selva, D. (2007) Periocular squamous cell carcinoma. Clinical \& Experimental Ophthalmology, 35, 174-185. http://dx.doi.org/10.1111/j.1442-9071.2006.01411.x

[24] DiGiovanna, J.J., Patronas, N., Katz, D., et al. (1998) Xeroderma pigmentosum: Spinal cord astrocytoma with 9-year survival after radiation and isotretinoin therapy. Journal of Cutaneous Medicine and Surgery, 2, 153-158. 